\title{
Corynebacterium minutissimum
}

National Cancer Institute

\section{Source}

National Cancer Institute. Corynebacterium minutissimum. NCI Thesaurus. Code C86317.

A species of aerobic or facultatively anaerobic, Gram-positive, coryneform, pleomorphic bacilli assigned to the phylum Actinobacteria. This species is nonmotile, non-spore forming catalase and pyrazinamidase positive, indole and urease negative, non-lipophilic, does not reduce nitrate, ferments glucose, sucrose and maltose, hydrolyzes hippurate, but not casein or gelatin. C. minutissimum causes erythrasma and pruritic scaly rashes in diabetic patients. 